\title{
Turismo, Hotelaria e Hospitalidade
}

\author{
Luiz Octávio de Lima Camargo ${ }^{1}$
}

RESUMO: Analisa o surgimento dos cursos de hotelaria, desdobrados da matriz dos cursos de turismo, e a polêmica sobre a denominação hotelaria ou hospitalidade. Esse desdobramento se insere dentro da dinâmica historicoideológica de evolução do campo das ciências aplicadas, notadamente no segmento mais amplo da comunicação, e a noção dehospitalidade, bem além de uma discussãosobre meras denominações, pode representar um acréscimo de significado e um quadro de referência original para os estudos na área.

PALAVRAS-CHAVE: turismo, hotelaria, hospitalidade, curso.

ABSTRACT: This paper analyses the arising of the Hotel Management Courses separated from the curriculum planning of the Tourism Courses and the polemic of naming hotelbusiness or hospitality. This separationbecomes part of the historic-ideological dynamic of applied sciences, precisely inthe sense that the idea of hospitality, muchmore than just a semantic discussion, may mean a relevant addition or even a different way of dealing with this subject.

KEYWORDS: tourism, hotelbusiness, hospitality, leisure, course.

\section{Introdução}

Os cursos de bacharelado em turismo são recentes no país. A Universidade Anhembi Morumbi, pioneira na área, abriu sua primeira turma em 1971. À época, mal

1. Bacharel em Comunicações com habilitação em Jornalismo pela Escola de Comunicaçōes e Artes da Universidade de São Paulo (ECA-USP). Doutor em Ciências da Educação pela University Sorbonne-Paris V. Docente do Programa de Mestrado em Hospitalidade da Universidade Anhembi Morumbi e docente colaborador do Programa de Pós-Graduação em Ciências da Comunicação da Escola de Comunicações e Artes da USP.

E-mail: oatacam@uol.com.br 
se delineava, no cenário econômico-empresarial, a força do setor do turismo, cuja pujança crescente estimulou a abertura de cursos (hoje já são mais de quatrocentos cursos em nível de bacharelado) em todo o país.

Pouco a pouco, dentro do turismo brasileiro, um subsetor passou a ganhar visibilidade e luz própria, a "indústria hoteleira", pressionando no sentido de um desdobramento dos estudos na área. Esse desdobramento, de início restrito aos cursos técnicos, avançou no ensino superior, sob a forma de cursos de Hotelaria (em nível de Tecnológo) e habilitações de Hotelaria em cursos de Administração. Daí ao desdobramento efetivo foi um passo. Os cursos de Turismo mal tinham atingido sua maioridade, e já surgia o curso de Bacharelado em Hotelaria.

Essa evolução, esse desdobramento e essa busca de autonomia, em relação ao curso de turismo, podem ser percebidas através de uma análise da evolução das matrizes curriculares da área. Esse estudo revelaria, sem dúvida, a mesma mudança paulatina: de início, as matrizes curriculares de hotelaria eram inteiramente baseadas na do turismo; pouco a pouco, porém, assumiram feições diferenciadas e hoje já são bastante distintas.

Se o movimento de desdobramento da matriz do curso de hotelaria, a partir da matriz do curso de turismo, é uniforme nos mais diferentes países, o mesmo não ocorre com a denominação do conteúdo desdobrado. Aqui acontece uma controvérsia. Nos países anglo-saxões, prefere-se a denominação hospitalidade ${ }^{2}$. Nos países latinos, adotou-se pura e simplesmente a denominação hotelaria.

Essa progressiva autonomia de currículos escolares afetou também a discussão sobre as relações conceituais em turismo e hotelaria. Afinal, hotelaria é uma instância do real distinta ou simplesmente uma parte do turismo?

Os recém-criados programas demestradomergulharamnessa mesma dinâmi ca evolutiva e, ao final, também nessa controvérsia. Como denominá-los? Hotelaria ou hospitalidade? Ou, inversamente, por que hospitalidade e não hotelaria? Ou melhor, por que não manter a simbiose inicial nas denominações turismo e hotelaria ou turismo e hospitalidade? Ou por que não simplesmente tratar a hotelaria como uma habilitação (no bacharelado) ou linha de pesquisa (no mestrado) de turismo?

Estas são as questões a que se propõe responder. Entre parêntesis: embora nunca se tenha detido particularmente na análise das relações de autonomia dependência entre as noções de turismo e hotelaria, no caso da denominação nunca se escondeu a preferência do autor pelo termo hospitalidade. A bem da verdade, em todas as vezes em que se participou desse debate, sempre se convenceu pelo argumento mercadológico da falta de tradição da noção de hospitalidade no país, que poderia induzir à idéia de hospital e não de hotel. Sentiu-se que a objeção ao termo hospitalidade vinha, assim, tão-somente do receio de colocar em risco a iniciativa por um mero problema de comunicação.

Deixa-se claro, desde o início, que nenhuma das questões é bizantina... Ou melhor, somente seria bizantina caso se reduzisse a uma questão de nomes; pouco importa o nome se aceitas as premissas da discussão. Um curso de hotelaria centrado

2. Em inglês, nem mesmo há uma palavra correspondente a hotelaria em questões da hospitalidade é preferível a um curso de hospitalidade restrito aos temas que cercam a hotelaria. Essas questões de denominação de uma área do conhecimento são sempre oportunidade, não apenas para a definição do objeto de estudo da área, como também para uma discussão epistemológica sobre outras questões que permitem refletir ou, ao menos, fornecem elementos para uma reflexão atual sobre os rumos da ciência e da universidade, tais como:

- até que ponto o mercado e a economia injetam vida à ciência e à universidade, e a partir de qual ponto essa convivência é simplesmente permissiva, tornando-se promíscua e passando a ser espúria?

- até que ponto a fragmentação das disciplinas científicas puras ou aplicadas é benéfica para a ciência, e a partir de que ponto a fragmentação simplesmentereflete disputas ideológicas exógenas aos seus interesses?

Antes de continuar, gostar-se-ia, se possível, de assegurar que a preferência já avançada pelo termo hospitalidade não seja vista como depreciativada designação de hotelaria, tão difundida em tantos cursos técnicos, de tecnologia e de bacharelado e sim como um convite a se ampliar o espectro de temas e de problemas de investigação.

\section{Por que Hospitalidade e nāo Hotelaria?}

A iniciativa de criação de um programa de mestrado na área (no caso, pouco importa a denominação de hotelaria ou hospitalidade) certamente está relacionada com a formidável expansão dos setores empresariais de hospedagem (sobretudo os hotéis)e de restauração, a que as sociedades globalizadas vêm assistindonas últimas décadas. Até aqui não há o que se discutir.

Há pelo menos quatro fortes argumentos para justificar a opção pelo termo hotelaria: o público dos cursos, o número crescente de cursos de formação profissional em hotelaria, o tema das pesquisas e, finalmente, o mais importante, a ambigüidade da noção de hospitalidade. Começaremos por este último.

Tanto os dicionários de língua portuguesa ${ }^{3}$ como os franceses ${ }^{4}$ e os ingleses ${ }^{5}$ mostram similaridades na designação do significado e na contextualização dessa noção. De um lado, existe a concordância no seu significado de hospedar alguém, já

\footnotetext{
3. "Ato de hospedar; hospedagem." (Dicionário Aurélio, Rio: Nova Fronteira, 1986) ou "1. Bom acolhimento dispensado a alguém. 2. Agasalho dado a hóspedes". (Dicionário Michaelis, 1998).

4. "Action de recevoir et d'héberger quelqu'un chez soi, par charité, liberalité, amitié". (Le Petit Larousse, Paris,

1993). Food, a phay to
} 
presente sem nenhum equívoco no significado de hotelaria $;$; de outro, a proximidade indutora a equívocos, para não falar de contágio semântico de outros termos etimologicamente (e na prática social cotidiana também) aparentados como hospício, hospital, hostilidade, hóstia (que ainda guarda do latim o significado de vítima). Aí, convenhamos, não há como adotar o termo hospitalidade sem assumir e mergulhar nessa ambigüidade. Sem dúvida, do ponto de vista prático de uma decisão pela opção entre um dos dois termos, émais fácil manter a designaçãohotelaria e incorporar, ainda que acessoriamente, a discussão sobre hospitalidade do que assumir a designação hospitalidade e explicar o que hospício, hostilidade, hóstia tem a ver com hotelaria.

Em seguida, não se pode ignorar que os segmentos de público mais importantes e que fornecerão a parcela mais significativa do contingente de alunos de um Programa de Mestrado em Hospitalidade serão, de um lado, profissionais envolvidos com a operação de hotéis e restaurantes e interessados em aprofundar seu conhecimento no campo e, de outro, docentes de escolas ligadas à formação profissional de pessoal de hotéis e restaurantes e preocupados em equipar-se adequadamente para essa função. Esses dois públicos reconhecem-se integralmente na noção de hotelaria, o mesmo não acontecendo com a noção de hospitalidade.

Não se deve esquecer que o número crescente de escolas e cursos em níve médio, tecnológico e de bacharelado vem adotando a designação hotelaria e a crescente demanda de docentes academicamente qualificados constituem exatamente as principais circunstâncias estimuladoras da criação de cursos de pós-graduação na área.

Finalmente,deve-selembrartambémqueénormalesperarque asquestões de pesquisa a serem trazidas pelos alunos girem exatamente em torno desses setores da hospedagem e da restauração, de problemas de gestão e da formação de pessoal correspondente.

Repetia-se, então, a primeira pergunta: já que todas essas razões militamem favor do termo hotelaria, por que propor a outra designação, hospitalidade? Assim já que se assume a preferência pelo termo hospitalidade, não resta senão explicitar as respectivas razões.

Alguns poderiam ser tentados a ver nesta opção apenas o objetivo de conferir estatuto de nobreza à área. Afinal, diferentemente do termo hotelaria, recém-chegado ao campo aplicado da ciência, o termo hospitalidade já conta com certa tradição no pensamento, tanto da filosofia como da ciência pura. A hospitalidade, como dever, comovirtudee comodireito, está presenteno pensamento mítico, religioso e científico dos mais diferentes povos. No pensamento grego, em especial, a hospitalidade figurava como um dever e foi objeto de sensíveis reflexões (Scherer, 1993).

A hospitalidade foie ainda éoprincípiobásicode um grande número de ordens religiosas católicas, desde os primeiros beneditinos e cistercienses, cujos mosteiros até hoje cultuam as regras originais da hospitalidade e muitos deles vêm se transfor- mando em hotéis e pousadas, até as mais recentes ordens e congregações religiosas. De resto, a noção de hospitalidade coaduna-se com os princípios básicos de todas as religiões e todas elas, sem exceção, têm um lugar de destaque para a idéia de hospitalidade?

Atualmente, no plano filosófico, a noção de hospitalidade vem ganhando crescente importância a partir do pensamento do filósofo francês Jacques Derrida, que a trouxe ao centro de uma discussão da maior relevância e pertinência, já que envolve os grandes êxodos migratórios de países pobres para países ricos. Para Derrida (1999), a hospitalidade é a bandeira de uma verdadeira cruzada contra a intolerância e o racismo, bem como a base do que ele chama de democracia total.

Do diálogo que ele travou com seu mestre, Emmanuel Levinas, em torno do conceito de hospitalidade (Levinas já falava em hospitalidade), Derrida vai desenvolver a noçăo do que seja hospitalidade, chamando-a de "hospitalidade incondicional"? É preciso estar aberto ao outro de maneira incondicional. Esse é o princípio da "democracia por vir". Năo uma democracia que preserva o todo, previamente, já delimitado, como por exemplo, a Europa comsuas histórias de guerrasinternas, comseusódios, seus bodes expiatórios e seus movimentos de expurgo constantemente renovados. Essa democracia que se produziu, que se produz, de que se fala, ela é fechada, uma democracia clássica, classicamente postulada, que tem seus inimigos que precisam ser rechaçados, em nome dessa identidade democrática. A noçăo de hospitalidade incondicional faz com que se pense para além desse fechamento democrático, dessa noçăo clássica de democracia. É preciso ir além das dicotomias, presentes hoje no mundo; uma abertura ao infinito, à alteridade, para o outro que está por vir e, também, para a noçāo de democracia que está por vir. Uma democracia que seria a ultrapassagem das fronteiras do ódio, das fronteiras da negaçăo do outro, constantemente praticadas, hoje, na Europa, ou em qualquer lugar, aqui no Brasil também, contra todas as variaçōes da noção de nacionalismo, que ele considera um fechamento, uma apropriaçăo de uma demarcaçăo, de uma inscriçăo demarcatória, uma territorialidade, uma expansāo dacrençade um "eu" absoluto. De modo que as noçōes de democracia e de hospitalidade incondicional passam pelo ato fundador de uma singularidade poética. A noçăo de hospitalidade incondicional cria um espaço de compaixăo, no sentido de ser possivel haver uma paixăo con-vivencial, uma paixăo pelo outro, num jogo que tem conflitos, mas que, pouco a pouco, eles possam ser transformados em uma experiência de abertura. (Trecho extraido de entrevista realizada em 9/4/99 com Luis Femando Medeiros de Carvalho, prof. titular da PUC-RJ e aluno de pós-doutorado de Derrida, disponivel no site <www.rubedo.psc.br> acessoem 30/7/01).

7. Utilizando o termo hospitalidade corno orientaçāo, qualquer buscador na intemet mostra a grande força do pensamento religioso (das mais diferentes confissões) sobre o tema. 
Ademais, é possível, com relativa facilidade, efetuar-se um recorte sobre hospitalidade no referencial sociológico, antropológico, histórico, etc. da ciência Não seria pois de todo infundada essa suposição de busca de certificado de nobreza, sobretudo se considerarmos que a hotelaria é uma ocupação modema herdada de antigos modelos servis de trabalho e essa origem, quer queira quer não queira, aceitese ou não, confesse-se ou não, traduz-se socialmente (mesmo dentro da academia, que não está infensa a esses fenômenos) em preconceito e desprestígio.

Também há aqueles que podem ver na iniciativa de adoção do termo hospitalidade o objetivo de evitar que o programa se confine apenas a práticas de um único campo de negócios, o que, aliás, não estaria errado. Estes, sem dúvida, contam também com certa dose de razão. Afinal, não há o caso de nenhum mestrado acadêmico (apenas mestrados profissionalizantes do tipo MBA) voltado à problemática de um único campo de negócios.

Em consequiência, não estariam errados igualmente os que enxergassem na opção pelo termo hospitalidade, a fuga do viés excessivamente econômico e empresarial para o curso que viria no bojo do termo hotelaria, como já acontece nos cursos de bacharelado em hotelaria, nos quais a ênfase humanista vem sendo ofuscada pela pressão do mercado de negócios e de trabalho.

Muito além disso, contudo, esta opção baseia-se na percepção de que o fenômeno digno de estudo é bem mais abrangente do que o crescente número de pessoas que busca hospedagem e alimentação em suas viagens. Na verdade, é a nova visibilidade adquirida nos tempos atuais pela hospitalidade humana, que extrapola não apenas os negócios ligados à hospedagem e restauração, bem como o próprio campo do turismo. Isto eqüivale a dizer que a noção de hospitalidade enriquece, enquanto a noção de hotelaria empobrece o campo de estudo.

Assim também,é claroque a formação de pessoal, apenas emnível operaciona ou apenas para atender à demanda de profissionais para hotéis e restaurantes, constitui justificativa suficiente para cursos técnicos de nível médio, quiçá para cursos superiores no nível de tecnólogo, mas não o é para o nível de bacharelado e menos ainda para a pós-graduação stricto sensu, instâncias que, mesmo contaminadas, ainda buscam manter-se acima e além das injunções conjunturais do mundo dos negócios. Em outras palavras e mais diretas: há que se fugir da sina e buscar ser algo mais do que o departamento de recursos humanos da indústria hoteleira.

Mais do que simplesmente exaltar as vantagens do termo hospitalidade sobre hotelaria, pretendemos demonstrarque o termohospitalidadeé mais heurístico, abrese uma ampla discussão e que a assunção da hospitalidade, enquanto objeto de pesquisa, significa aceitar tanto o risco como a oportunidade derivados da ambigüidade da primeira noção, na medida em que esta induz a um duplo movimento epistemológico do conhecimento sobre os meios de hospedagem e restauração, um primeiro de distanciamento crítico e um segundo de reaproximação crítica.

O primeiro é o de afastar-se criticamente e analisar esses segmentos empresariais da hospedagem e restauração, seus operadores e formadores, a partir de uma perspectiva mais ampla, que abrange o conjunto de valores, modelos e ações que dizem respeito ao receber humano. Tal perspectiva permite que aflorem novos temas
- impensáveis, que não são abordados hoje nem pela hotelaria nem pelo turismo (ou que o são apenas muito superficialmente), e que são imprescindíveis a uma reflexão que se desloca dahotelaria para a hospitalidade-, tais como a conversação, a etiqueta, a postura social, o dom, o cerimonial, a festa, em suma, os ritos da hospitalidade. Um programa de bacharelado ou, mais ainda, de mestrado que aceite esta premissa certamente será obrigado a dar tanta ênfase a estes temas já estudados pela história, sociologia, antropologia, como os inevitáveis temas da gestão da recepção, controladoria, governança e alimentos e bebidas.

Um segundo movimento, de reaproximação crítica, permite que se percebam todas as instâncias concretas envolvidas com o receber humano, num primeiro momento, no plano da recepção turística e, num segundo momento, todas as circunstâncias do fazer humano objetivamente envolvidas com o ato de receber pessoas. Assim colocado o problema, resulta claro que hotéis e restaurantes são apenas o princípio de uma série de itens da hospitalidade, que inclui ainda, bufês, organização de eventos, organização de festas e cerimoniais, enfim, a totalidade do chamado receptivo turístico de uma cidade, bem como (e aqui já estamos fora também do campo do turismo, já que se destinam também a populações locais) hospitais, clínicas de saúde, hospícios, prisões e, até mesmo, os serviços de recepção de qualquer órgão, setor ou empresa.

Em resumo: denominar o programa de hospitalidade tem duplo significado epistemológico. Em primeiro lugar, permite operar um recorte não apenas do campo coberto pelas disciplinas dos cursos de turismo, como de outras ciências aplicadas. Em segundo lugar, a opção pode ser entendida como resistência ideológica à vinculação do pensamento acadêmico a um campo que é apenas um campo de negócios e, como tal, impossível de ser estudado isoladamente de campos assemelhados.

Uma última justificativa poderia ser arrolada como corolário das anteriores e que se insere no mesmo contex to econômico que estimulou a criação do curso: ao se falar em hospitalidade o espectro de ocupações possíveis é bem amplo do que simplesmente hotelaria. O profissional da hospitalidade é, não apenas o do hotel e do restaurante, mas também o que atua em todo o sistema receptivo turístico de uma cidade e o que atua em órgãos e empresas que de alguma forma acolhem os habitantes da própria cidade.

\section{Por que Hospitalidade como Programa Específico e nāo como Linha de Pesquisa?}

Esta questão já foi, em parte, tratada e antecipada nas respostas à questão anterior. O que vem a seguir, contudo, não é uma repetição. Trata-se muito mais de uma recolocação de idéias, não mais sob o ângulo da dependência da ciência à empresa privada e à economia e muito mais sobre os caminhos da divisão das disciplinas científicas. 
Parece inegável que a explosão meteórica de cursos ligados aos diversos ramos aplicados da ciência, como nos campos da saúde (medicina, enfermagem, terapia ocupacional, nutrição, dietética, fisicultura, etc.), da educação (educação física, educação artística, educação ambiental, etc.), da administração de empresas (bancária, escolar, etc.), entre outros foi determinada não apenas pela importância científica dos novos conhecimentos, mas também por um contexto ideológico adequado que favoreceu, estimulou e utilizou esses novos conhecimentos presumidos ou reais segundo sua própria lei e lhes conferiu seu prestígio.

Já é sobejamente estudada a circunstância ideológica que presidiu à ênfase hoje atribuída pelos órgãos educacionais centrais do país aos campos aplicados do conhecimento em detrimento das ciências puras, sobretudo das ciências sociais humanas (Camargo, 1986; Demo, 1994). Já se conhece o suficiente, sem necessidade de nisso insistir, o significado ideológico de uma universidade mais próxima do mercadoe mais distante dareflexão especulativa. Esta ênfase na ciência aplicada, de início assentada na lógica de controle político pela ditadura militar que se implantou no Brasil na década de 60 - para a qual as ciências puras como a sociologia, a antropologia, a história eram fontes de valores de contestação ao regime que se implantava - posteriormente teve o respaldo de um modelo de desenvolvimento econômico que necessitava de apoio da universidade para o seu incremento. À ideologia política, assim, sucedeu à ideologia econômica, ao menos no primeiro plano da análise, já que para muitos analistas ambas estiveram sempre juntas.

Aliás, diga-se que este fenômeno acompanha o próprio nascimento das diferentes ciências. A economia firmou-se como ciência apenas depois que a sociedade refutou as normas de inibição do lucro e do capital presentes no coração do sistema escolástico. Se a história foi-se organizando nos planos de estudo do ensino primário, secundário ou universitário, como disciplina acadêmica, não foi somente em função de motivos científicos, mas também em função da dialética ideológica dos Estados nacionais diante da Igreja e dos Estados nacionais entre si

Este trajeto aplica-se integralmente àquilo que se observa ao longo do desenvolvimento dos cursos ligados ao entretenimento. Emblematicamente surgidos em 1968, os cursos de comunicação (jomalismo, editoração, biblioteconomia radio, tevê, publicidade, cinema, teatro, etc.) respondiam não apenas aos conflitos estudantis ocorridos em torno das faculdades de filosofia e ciências sociais da USP, como ao desabrochar da economiada comunicação de massa no país, agoraem escala

\footnotetext{
8. No pensamento marxista, a ideologia é uma concep̧̧ão da ação e, portanto, unn atributo da superestrutura. As forças produtivas mais o modo de produção (a estrutura social, a organização da propriedade, as funçōes sociais, a luta de expressão do ("falsa consciência"). Contudo, pode ser progressista ou reacionária. Se esta representa a totalidade das forcas produtivas é una ideologia progressista. Se mantém as relações de dominação, é reacionária(Grawitz, 1974:120-1). Entenda-se aqui ideologia, no seu sentido filosófico mais elementar, como a visão distorcida provocada pela posição especial do agente no campo decisório e seus interesses. Invocando o contexto ideológico, estamos ao mesmo tempo perguntando: a quem interessa a decisão?
}

industrial ${ }^{9}$, que posteriormente diversificou-se agregando as áreas de lazer, turismo ehotelaria.

A cada novo desdobramento, a cada disciplina que se instala, a mesma dinâmica se instaura. A nova disciplina da ciência aplicada passa a ter, também, uma ação ideológica própria. Tem que disputar terreno com as demais; mais ainda, somente pode crescer reivindicando parte dos campos e dos objetos de estudo que vinham sendo cultivadas por disciplinas já estabelecidas e, neste sentido, não apenas deve distinguir-se e emancipar-se delas - daí o novo nome-, como também tentará submetê-las. Taléo início do processoque desemboca na tentativa de "imperialismo" de tantas disciplinas particulares novas (Bueno, 1995) e que é o princípio ativo dos ismos correspondentes (sociologismo, economicismo, historicismo, psicologismo, antropologismo, biologismo...). Foi o que ocorreu também com o jornalismo em relação às demais áreas da comunicação e, atualmente, com o turismo em relação a hotelaria, lazer e eventos.

É certo, também, que a entronização de um novo nome de uma disciplina implica essencialmenteuma reorganização, de alguma maneira, do campo das ciências na qual esta se insere. A nova disciplina, como se fora uma forma vivente, há de introduzir-se entre as outras, obedecendo à lei implacável da luta darwiniana pela sobrevivência do menos inviável. E, a esta altura, mais do que nunca, a designação da disciplina é essencial, pois é essa preocupação que preside à discussão epistemológica sobre o campo e o objeto dessa disciplina e sobre o processo de reorganização do campo mais amplo.

Essareorganização, no caso das ciências puras, não acontece comouma forma de acumular saber aos saberes tradicionais, mas quase sempre como ruptura(Grawitz,1974:92). A economia teve que abrir caminhoem conflitocoma moral, que pretendia por limites nas leis do lucro do capital, em função da nova situação dos estados colonialistas; a sociologia desvinculou-se da filosofia; a psicologia opôsse à teologia e à filosofia; a história, em competição não somente com a história da Igreja, mas também com a sociologia.

No campo das ciências aplicadas, a ruptura é secundária, parecendo mais evidente a disputa encarniçada pelo espaço de ação e pela importância no contexto acadêmico. A hospitalidade, a recém-chegada ao universo das ciências aplicadas, repete a mesma saga das lutas anteriores de competição com outras disciplinas pela conquista de status como instituição acadêmica com direito próprio (denominação,

9. Cabe aqui uma explicação sobre as relações entre os campos da comunicação e do entretenimento. Os egressos das escolas de comunicação (sobretudo os jornalistas) sentem-se pouco à vontade quando catalogados dentro do campo do entretenimento. Ficariam menos constrangidos se confrontados à evidência de que o lazer das pessoas é na sua quase totalidade vivido dentro das casas e, dentro das casas, metade desse tempo de lazer é circunscrito por meios de comunicą̧ão de massa em geral (tevê, rádio, publicidade, jomais, revistas, "games" eletrônicos, etc.). Já tive a oportunidade de me deter mais longamente nesta análise (Camargo, 1998: 132-133). Em decorrência, ainda, entenderiam melhor porgue os cursos de turismo, lazer e hotelaria surgem nos departamentos de comunicação das universidades, mais ate mesmo do que nos departannentos de administraçăo, como seria lógico dentro da ótica mercadológica, ou da educą̧ão, como seria lógico dentro da gênese dos problemas (sobretudo o lazer surge em diferentes sociedades como uma preocupação, de início, educacional). Resumindo, poder-se-ia colocar a hipótese de que a Academia ainda é conservadora a ponto de não aceitar o termo entretenimento, mas é lógica o 
financiamento, cátedras, departamentos, horários nos planos de ensino). Naturalmente, as disciplinas mais próximas têm toda razão em temer que esta nova disciplina invada abusivamente as suas próprias searas tentando abocanhar um naco de problemas científicos e (o que é mais importante) de espaço acadêmico. Esta própria reflexão aqui entabulada pode ser colocada nessa perspectiva.

Em tempo: da mesma forma como seria ingênuo supor que todas as ciências, puras e aplicadas, surgem apenas do zelo de estudiosos interessados no progresso do conhecimento, seria injusto atribuiro processo exclusivamente a intuitos exógenos à ciência, de leitura ideológica patente ou velada. Assim, esta análise seria parcial se esquecesse, nesse caminho, da participação de agentes da ciência seriamente imbuídos de desígnios genuínos de fazer avançar o conhecimento científico. Parafraseando a sátira de Bachelard sobre a psicanálise, o esterco não explica a rosa. Não obstante os desvios e seqüelas decorrentes da ideologia político-econômica subjacente à sua implantação, os diferentes cursos de comunicação figuram entre os mais produtivos cientificamente no momento. E os campos do turismo, lazer e hospitalidade caminham celeremente na mesma direção.

Estas breves linhas apontam para três circunstâncias envolvidas, comocausa ou efeito, com a divisão dos campos da ciência pura ou aplicada:

- da parte de alguns, um genuíno interesse em ampliaro conhecimento naquela área - é evidente que muitos acadêmicos, de um lado incapazes de lutar contra o esvaziamento de suas áreas de origem, sentem-se verdadeiramente estimulados em estudar a dinâmica deste novo e poderoso setor da ação social e econômica;

- da parte do poder políticoe/ou econômico, uma tentativade manter a ciência dentro da lógica de seu interesse de poder - naturalmente, o setor de hospedagem e restauração é hoje tão significativo, dentro do turismo, como o ligado à viagem;

- da parte da disciplina emergente, mais do que interesse, a necessidade de disputar espaço com outras áreas da ciência, de forma a viabilizar-se: os cursos ligados à hospitalidade desejam dividiro "bolo" doconhecimentoantes açambarcado pelos cursos de turismo, assim como a do conhecimento restrito a outros cursos como relações públicas, nutrição e dietética, etc., bem como efetuar um recorte de disciplinas como filosofia, sociologia, antropologia.

No fundo, trata-se de iniciar um longo caminho na direção da delimitação daquilo que, no futuro, poderá constituir o campo multidisciplinar das ciências da hospitalidade, com um recorte específico não apenas das ciências, como a antropologia, sociologia, história, geografia, economia, e política etc., como também das ciências aplicadas da administração, educação, comunicação, arquitetura, urbanismo etc.

\section{A Caminho das Ciências da Hospiłalidade}

A constituição de um campo aplicado da ciência acontece não apenas, como já foi ditomo o, reivindicando parte dos campos e dos objetos de estudo que vinham sendo cultivadas por disciplinas já estabeiecidas. Acontece, sobretudo, demonstrando que o novo nome não serve apenas para distingui-la e emancipá-la, mas sobretudo para trazer ao cotidiano da pesquisa novos temas e novas preocupações, vale dizer, uma nova forma de conceituar e formatar a realidade como objeto de pesquisa.

Trata-se, para utilizar uma noção mais precisa, de dotaro novocampodeuma relativa autonomia em relação aos campos já estabelecidos. Os novos campos acadêmicos do saber surgem como resposta a demandas ideológicas externas de ordem variada - eis aí uma constatação (para muitos simplesmente um truísmo) já analisada acima, da qual uma nuança nos interessa agora: é que, na sua formatação, eventualmente esse novo campo acadêmico se insere num novo movimento ideológico de resistência e de contestação da própria lógica que o criou. Criar um programa de mestrado e denominá-lo Hospitalidade, ao invés de Hotelaria, pode, assim, representar a alternativa que se encontrou em favor de um resgate das grandes questões da ciência para a sociedade, utilizando para recorte as questões ligadas ao tema da hospitalidade.

O objeto de pesquisa deixa de ser apenas e tão-somente o turista em viagem que busca um quarto ou uma refeição podendo ser também o migrante, o estrangeiro, o diferente, o estranho. A problemática da governança ou conciergeria de um hotel, do "maître" de um restaurante, da organização de eventos emnada perde se estudada à luz deu mreferencial teórico mais amplo que considera a situação de todo equalquer indivíduo afastado de seu nicho social e cultural e que busca o calor e respeito humanos de um empregado de um hotel, dos organizadores de um evento, de uma comemoração, daquele que é portador de uma informação para ele necessária ou mesmo vital. Ou, inversamente, permite que se estude sob uma nova luz a situação insólita de profissionais exercendo metiês que, na sociedade tradicional, eram simplesmente servis e vivendo hoje a contradição de estarem entre os mais bem remunerados do mercado de trabalho.

Ainda que arriscado no atual estágio de desenvolvimento do pensamento acadêmico na área, pode-se mesmo sonhar colocarem-se um dia as questões com que se debatem as nações ricas atuais diante de êxodos migratórios provenientes de países pobres, com os mesmos instrumentais de análise do receptivo turístico. Esta iniciativa pode conduzir a interessantes análises sobre o momento político atual.

Fique bem claro desde o início: não há nenhuma objeção a toda a literaturaque hoje se produz sobre gestão dos meios de hospedagem e restauração como conteúdo da hospitalidade. Se aqui não se faz menção, porque tal literatura já é dominante nos cursos de hotelaria. As sugestões que seguem são acréscimos com vistas a dotar a área da hospitalidade da necessária relativa autonomia em relação aos campos do turismo e da administração, aos quais estão mais estreitamente ligados hoje.

Dessa forma, tomando-se a bibliografiajáexistente, podem ser estabelecidos alguns recortes para a definição do objeto de estudo das ciências da hospitalidade. Esta epistemologia da hospitalidade, aqui ensaiada, deverá ser uma das prioridades da reflexão e da pesquisa no setor. 
Ainda dentro da filosofia, poder-se-ia continuar o esforço de delimitar ontologicamente a hospitalidade, como Elisabeth Telfer (Lashley \& Morrison, 2000: 38-55), tentando diferenciar o anfitrião do indivíduo capaz da qualidade da "hospitalidade" ("hospitableness"), sem esquecer o estudo da hospitabilidade como virtude, bem como a ética da hospitalidade. Uma associação de ética e estética a hospitalidade poderia encontrarna "finalidade sem fim" de Kant(1994) uma boa pista de pesquisa. O mesmo Kant poderia introduzir o estudo da ludicidade, do prazer associado à ação da hospitalidade. Isto permitiria entender o lazer não apenas como um dos campos de preocupação do anfitrião em relação ao seu hóspede, como também uma categoria para análise da própria ação hospitaleira, do prazer de receber.

Aliás, uma sociologia da hospitabilidade poderia começar por recortar as análises do caráter receptivo (em oposição a ativo) do lazer em tantas circunstâncias (Camargo, 1998: 108-115). Poderia, ademais, devendar estilos de hospitalidade associados a classes sociais, inspirando-se em Pierre Bourdieu (1983), ou como estilo de "tribos", inspirando-se em Michel Maffesoli (1987). Na pista deste último, há a chance de estudar o imaginário que formata a prática social da hospitalidade (Montandon, 1999; Eliade, s/d).

A sociologia da hospitalidade poderia ainda seguir a pista da transformação deestilos servis de trabalho das sociedades tradicionais em profissões modernas bem posicionadas no mercado de trabalho: do mordomo ao maître, do cozinheiro ao "chef", do tutor ao animador, etc. Neste caso, seria um referencial crítico capaz de desnudar o ridículo de estilos de hospitalidade que nada mais são do que caricaturas de práticas associadas ao "ancien régime", quandoo servilismo afronta os limites do politicamente correto. A esta altura, já estamos em condições de refletir sobre a própria evolução do conceito tradicional de etiqueta, de marcada preocupação mundana, de afirmação de origem de classe social, para o atual conceito de etiqueta, mais psicológico, afirmador da necessidade de se estar bem, de "centração" da postura. No caso brasileiro, tal meta poderia ser fixada mediante a análise da evolução da noção de etiqueta de Marcelino de Carvalho (1966) a DanuzaLeão(1992). Ou, mais profundamenteainda, como o fêz Renato Janine Ribeiro(1999), desvelar a nobrezaancestraldo conceito de etiqueta que se perdeu na vida mundana das burguesias modernas.

E onde foi parar a "arte da conversação", tão valorizada no início da idade modema como forma de disciplina social (Elias, 1983; Burke, 1995) e que, hoje, sufocada pelos meios de massa, ensaia seu retorno como simples manifestação do humano (Millon, 1999; Zeldin, 2001)? Ecomo abordar o tema da conversação humana sem ter em mente sua importância diante do próprio fenômeno humano, como expressão - ludicidade - e como finalidade instrumental similar à do trabalho?

Háde se dar razão a Lashley\&Morrison de incluírem, também, em sua obra um capítulo sobre o humor na hospitalidade (2000:198-216) e todas as cenas picarescas do cotidiano, envolvendo o contato com a diferença e entre as diferenças entre as pessoas (étnicas, de atributos físicos e psicológicos, de profissões, etc.). O humor não é exclusivo da hospitalidade, masé, certamente, nos rituais da hospitalidade que encontra o terreno mais fértil para desabrochar.

Uma psicologia da hospitalidade poderia estabelecer perfis de anfitriões e perfis de hóspedes, bem como tentar delimitar, explicitar e estabelecer as bases para a solução de conflitos, como já o fizeram Darke\&Gurney (Lashley \& Morrison, 2000: 77-99), da mesma forma que uma sociopsicologia poderia dar eco aos estudos de Serrès $(1991 ; 1993)$ sobre a educação que se processa no contato com o diferente. Como ele bem lembra, pedagogo era o escravo que conduzia o pequeno na viagem, "a viagem com o outro em direção à alteridade"(1993:60).

Ainda há todo o campo da antropologia em aberto. A hospitalidade nunca foi uma noção central nessa ciência, mas sem dúvida esta pode fornecer os elementos básicos para um estudo comparado de modos de receber tanto num plano histórico - e aqui todos os estudos da história da vida privada cotidiana vêm a ser oportuno, mesmo no Brasil (Mello e Souza, 1997), quanto os estudos sobre as práticas de hospitalidade das populações ditas primitivas, sejamos clássicos de Mauss (1974:41184) sobreo dome a dádiva, sejamos de Gilberto Freyre (1987;2000) sobrea sociedade pré-industrial ou como os de Mello e Souza (1964) sobre a nossa sociedade caipira, como, finalmente, sobre os estilos de hospitalidade das diferentes sociedades atuais, ameaçados pela globalização e decorrente invasão de modelos estardardizados, sejam de práticas culturais sejam de estilos arquitetônicos, expressão de uma arquitetura e de uma gestão que não considera a identidade cultural local que Boorstin,(1987) corretamente definiu como "não-lugares"e "não-eventos".

Ao longo da história, tanto a hospitalidade social (das cidades) como a individual estão marcadas pela prática da festa. O estudo do evento moderno como desdobramento - evolução e ruptura - da festa tradicional pode encontrar apoio nas pesquisas de Cox (1974), de Dumazedier (1994)e de Duvignaud (1973).

Na mesma linha, a sociologia urbana teria muito a se beneficiar de uma perspectiva urbanística assentada na ótica da hospitalidade, que entenderia a cidade como um todo e seus espaços de circulação e lazer, em especial, como espaços receptivos da população local e turística.

Há, finalmente, o campo dos alimentose bebidas. Também aqui a literaturahoje dominante nos estudos de hotelaria e gastronomia, marcadamente ligada à gestão, não deveser esquecida, podendo, isto sim, ser sensivelmente ampliada para além dos limites da hotelaria e da nutrição.

Cabe, sem dúvida, uma consideração sobre os aspectos filogenéticos da alimentação humana, que podem ser estimulados

que a associam à estética (1965:85-105 v. II). É emblemática para a área também a reflexão de Brillat-Savarin (1998) sobre a gastronomia como uma decorrência da hospitalidade total e mesmo a revisão de sua obra à luz da moderna neurobiologia (Amat \& Vincent, 2000). Como campos correlatos, há que se lembrar o asseio e a higiene, desde os estudos de Malinovski (1974:423-447), passando pela revolução pastoriana da higiene até a nova revolução da higiene e dietética, ecológica, dos dias atuais.

Os espaços de restauração (bares e restaurantes) também podem ser reestudados à luz da sociologia, como instâncias privilegiadas, mais do que para comer e beber, para os prazeres da ludicidade humana, o ver e ser visto, a contemplaçãoe oencontro (Dumazedier, 1978: 105-113). 
Finalmente, a hospitalidade pode, mais do que recortar, obrigar a uma reelaboração e compensação das lacunas deixadas pela leitura da realidade hoje efetuada por outras disciplinas. Como ilustração, tomemos um exemplo extraído da leitura dos compêndios turísticos. Nesses livros, como é natural, o fenômeno das migrações turísticas contemporâneas é elaborado sob a ótica do viajante e não do viajado, das populações turísticas e não das populações receptoras. Sejamos, contudo, precisos para se evitarem mal-entendidos que comprometam a totalidade da discussão! Certamente os estudos turísticos são sensíveis aos problemas das populações visitadas. Todos os manuais de orientação de estudos de impacto ambiental do turismo, em especial as obras de Beni (2000), Ruschmann (1997) são sensíveis em alertar contra um turismo predatório que não considera a problemática das populações locais, contra a depredação do patrimônio cultural local. Tudo isto é verdadeiro. Mas, aceitemos também que a ótica da análise e sua prioridade é a do viajante, do turista e não das populações locais.

O exemplo das discussões sobre o turismo rural é oportuno. É comum notarse em congressos um conflito entre a perspectiva do profissional do turismo, essencialmente favorável ao desenvolvimento desse segmento e minimizador dos eventuais impactos naproduçãorural, e dos engenheiros agrônomos e florestais, que entendem o turismo rural como uma ameaça ao laço do habitante local com a produção agrícola. Pode-se dizer que o profissional do turismo adota a perspectiva da economia turística e da necessária expansão de suas fronteiras, o engenheiro agrônomo e florestal assume a defesa da economia agrícola e suas fronteiras. Contudo, por mais importante que sejam tanto o turismo como a produção agrícola pergunta-se: quem assumirá integralmente a perspectiva do habitante local, suas aspirações e expectativas? O ponto de vista aqui defendido é de que essa perspectiva do habitante local pode e deve serum dos domínios privilegiados das ciências aplicadas à hospitalidade.

\section{A Título de Conclusāo}

Acredita-se ter dado um passo à frente, possibilitando ou pelo menos lembrando um enorme elenco de alternativas de pesquisa que abrem, com o simples deslocamento do eixo de preocupação, a reflexão da hotelaria para a hospitalidade.

Mostramos comooptar por hotelaria significa aceitarque a missão estratégica dos cursos é formar profissionais para atender às necessidades epidérmicas do mercado de trabalho e que, neste caso, não há por que ir além do atual corpo básico de temas - no ensino e na pesquisa - associados à gestão da recepção, governança, controladoria, alimentos e bebidas, com um suplemento de temas associados a campos correlatos - eventos, recreação, nutrição - e de cultura geral.

Aponta-se, em seguida, as vantagens de uma troca pela designação e pelo corpo cultural abrangido pela denominação hospitalidade e o quanto esta opção enriquece a perspectiva de ensino e pesquisa no setor.

Alguns poderiam objetar que a limitação imposta à compreensão do real pela palavra, seja por imprecisão, seja por ambigüidade, enfraquece decisi vamente. Não obstante, o maior valor heurístico de uma denominação sobre outra, termina-se por trocar uma parcela do real delimitada de forma precisa, por outra imprecisa e ambígua. Hotelaria, bem ou mal sabe-se o que é, do que se trata, enquanto hospi talidade efetua um recorte no real difícil de ser formulado globalmente. Ao trocar-se hotelaria por hospitalidade, como se propõe aqui, troca-se um recorte, pelo menos, preciso por um impreciso e ambíguo, dois obstáculos à observação empírica na qual a ciência se baseia

Pode ser, mas, ao menos, discutiu-se. E a discussão é, sem dúvida, o pressuposto epistemológico da ciência. Melhor: convidamos todos os interessados no domínio da hospitalidade a refletir e a pesquisar esta questão. Nossa convicção final é que, confrontada com a noção de hospitalidade, é impossível pensar os meios de hospedagem da mesma forma anterior, apenas como um constructo de gestão.

Da mesma forma, espera-se que estas reflexões tenham sido úteis para aqueles que ensinam e pesquisam nos campos correlatos do turismo, do lazer, da comunicação. É saudável imaginar que estas reflexões possam, de alguma forma, ter a necessária continuidade numa sociedade futura na qual a criação/pesquisa tenha o lugar privilegiado que merece. Aquilo que hoje parece supérfluo, irrelevante, poderá exibir toda a sua força, como aconteceu com a noção de lazer no seu primeiro surgimento.

Espera-se que as ciências aplicadas ao turismo (enquanto a teorologia, a sonhada ciência da viagem não chega), as ciências aplicadas ao lazer e as ciências aplicadasà comunicaçãoem geral percebam a riqueza deum recorte do conhecimento científico moldado sobre ofenômeno ou o fato social associado ao gesto humano de receber.

\section{Referências}

AMAT, Jean-Marie \& VINCENT, Jean-Didier. 2000. Pour une nouvelle physiologie du goût. Paris: O. Jacob. BENI, Mário Carlos. 2000. Análise estrutural do turismo. 3. ed, São Paulo: SENAC.

BOURDIEU, Pierre. 1983. Questôes de sociologia. São Paulo: Marco Zero.

$\overrightarrow{B O O}$. 1994. Sociologia. São Paulo: Atica.

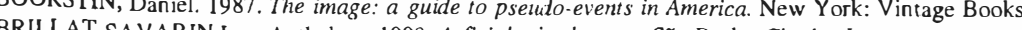

BRILLAT-SAVARIN,Jean Anthelme. 1998. A fisiologia do gosto.São Paulo: Cia das Letras.

BUENO, Gustavo. 1995. ¿ ¿ué es la ciencia? Oviedo: Pentalfa.

CAMARGO Peter. 1995. A arte da conversação. São Paulo: UNESP.

CAMARGO, Luiz Octávio de L. 1986. Novas tecnologias de comunicação: democracia cultural ou ideologia da modemização? In: FADUL, Ana Maria (Org.). Novas tecnologias de comunicação: impactos políticos, culturais 1998. Educos. São Paulo: Summus

$\widehat{C A R}$ VALHO, Marcelino de Lazer. São Paulo: Moderna.

CAX, Harvey. 1974. A festa dos foliđes. Petró Solis: Valo: Cia.Ed.Nacional.

dos folides: Petropolis: Vozes.

Rio de Janeiro: Tempo Brasileiro

DERRIDA \& DUFOURMANTELLE. 1997. De l'hospitalité. Paris, Calman-Lévy.

- 1994. A revoluçäo cultural do tempo livre. Säo Paulo: Studio Nobel. 
DUVIGNAUD, Jean. 1973. Fêtes et civilization. Paris: Weber.

ELIADE, Mircéa. s/d. O sagrado e o profano: a essência das religiôes. Lisboa.

ELIAS, Norbert. 1983. O processo civilizador - Uma história dos costumes. Rio: Zahar.

FREYRE, Gylberto. 2000. Sobrados e Mocambos. São Paulo: Record.

1987. Modos de homem e modas de mulher. Rio de Janeiro: Record.

GRAWITZ, Madeleine. 1974. Méthode des sciences sociales. Paris: Dalloz.

KANT, Emmanuel. 1994. Anthropologie d'un point de vue pragmatique. Paris: Vrin.

LASHLEY, Conrad \& MORRISON, Alison. 2000. In: Search of hospitality - theoretical perspectives and debates.

Oxford: Butterworth-Heinemann.

LEĀO, Danusa. 1992. Na sala com Danuza. São Paulo: Siciliano.

LEROI-GOURHAN, André. 1965. O gesto e a palavra. Lisboa: Ed.70. Vol. II.

MAFFESOLI, Michel. 1987. O tempo das tribos. Rio: Forense.

MALINOWSKI, Bronislau. 1983. A vida sexual dos selvagens. Rio de Janeiro: Francisco Alves.

MAUSS, Marcel. 1974. Sociologia e Antropologia. São Paulo: EDUSP. Vol. II.

MELLO E SOUZA, Antônio Cândido. 1964.Os parceiros do Rio Bonito. São Paulo: Duas Cidades.

MELLO E SOUZA, Laura (Org.). 1997. História da vida privada no Brasil. São Paulo: Cia. das Letras.

MILLON, Alain. 1999. L'Art de la conversation. Paris: PUF.

MONTANDON, 1999. Alain. Mithes et représentations de l'hospitalité. Clermond Ferrand: Presses Universitaires Blaise Pascal.

RIBEIRO, Renato Janine. 1999. A etiqueta no Antigo Regime. São Paulo: Moderna.

RUSCHMAN, Doris. 1997. Turismo e planejamento sustentável. Campinas: Papirus.

SCHERER, René. 1993. Zeus hospitalier: l'éloge de l'hospitalité. Paris: Armand Colin.

SERRES, Michel. 1991. O contrato natural. Rio: Nova Fronteira.

1993. Filosofia Mestiça. Rio: Nova Fronteira.

ZELDIN, Theodore. 2001. Conversação. Rio: Record.

Recebido em: $8 / 8 / 01$

Aprovado em: $28 / 9 / 01$ 